\title{
Texture Characteristic of Local Binary Pattern on Face Recognition with Probabilistic Linear Discriminant Analysis
}

\author{
$1^{\text {st }}$ Isnawati Muslihah, $2^{\text {sd }}$ Muqorobin \\ ${ }^{1,2}$ Institut Teknologi Bisnis AAS Indonesia Surakarta \\ ${ }^{1,2}$ Jl. Slamet Riyadi No. 361 Windan, Makamhaji, Kartasura, Sukoharjo, Indonesia \\ 1.isnawatimuslihah12345@gmail.com, ${ }^{2}$ robbyaullah@gmail.com
}

\begin{abstract}
Face recognition is an identification system that uses the characteristics of a person's face for processing. There is a feature in the face image so that it can be distinguished between one face and another face. One way to recognize face images is to analyze the texture of the face image. Texture analysis generally requires a feature extraction process. In different images, the characteristics will also differ. This characteristic will be the basis for the recognition of facial images. However, existing face recognition methods experience efficiency problems and rely heavily on the extraction of the right features. This study aims to study the texture characteristics of the extraction results using the Local Binary Pattern (LBP) method which is applied to deal with the introduction of Probabilistic Linear Discriminant Analysis (PLDA). The data used in this study are human face images from the AR Faces database, consisting of 136 objects (76 men and 60 women), each of which has 7 types of images Based on the results of testing shows the LBP method can produce the highest accuracy with a value of $95.53 \%$ in the introduction of PLDA.
\end{abstract}

Keywords-Texture characteristic, Local Binary Pattern (LBP), Local Ternary Pattern (LTP), Probabilistic Linear Discriminant Analysis (PLDA)

\section{INTRODUCTION}

The face is the main identity used to recognize someone, this is what inspires so many research on face recognition for identity. Feature-based introductions can be grouped into three groups: color, shape, and texture [1].

The texture is one of the basic elements of the image, which has brightness, color, slope, size and more. In general, textures form certain patterns repeatedly that meet most or all of the image area. In digital image processing, texture can be used to identify and recognize an image with certain characteristics based on the given texture recognition. Each area in the image has unique characteristics, to get a useful feature extraction is required to take the different characteristics of each region on the texture image [2].

The feature extraction process is very important in the pattern recognition phase because it is one of the things that determines the high level of face recognition. Besides, the extraction process also plays a role in the speed process in the process of recognition [3]. Feature extraction as a feature description stage in a numerical form of an image has a variety of methods. Several methods in the facial feature extraction process have been found, especially in this study comparing the characteristics of the texture produced by the Local Binary Pattern (LBP) and Local Ternary Pattern (LTP). Furthermore, the results of feature extraction will then be classified using the Probabilistic Linear Discriminant Analysis (PLDA) method, which is a method of generative probabilistic component analysis that generally combines knowledge about class labels and then introduces specific classes and specific samples in latent space. In the study of Wibowo, et al. [4] several PLDA approaches have been tested in two different databases and optimal recognition rates $(0.943-1,000)$ were obtained. This approach shows that PLDA's performance is very good at various expressions. However, the use of PLDA for face recognition is less varied with various types of feature extraction methods. Because face recognition depends on proper feature extraction [4].
Based on the background described, to optimize the application of PLDA as a face recognition method, it was decided to conduct research using the LBP and LTP approaches for feature extraction, namely by using the texture and shape features of an image, then converting grayscale images into binary numbers [5].

\subsection{System Architecture}

\section{RESEARCH METHODS}

The overall system architecture in this study can be seen in Figure 1. This figure shows how the system flows from the input image to get the result in the form of an identity label. In general, the system architecture consists of 3 parts, namely pre-processing, recognition, and testing.

The image input used is not obtained from image acquisition in the form of self-image taking in the form of an image but takes from the available AR Face database. The first step taken is the preprocessing of the image obtained. This is intended to prepare the image as desired. Pre-processing consists of the crop, resize and feature extraction. The feature extraction methods used are Local Binary Pattern (LBP) and Local Ternary Pattern (LTP). Then the extracted image will be processed in the recognition of PLDA so that the test results are obtained.

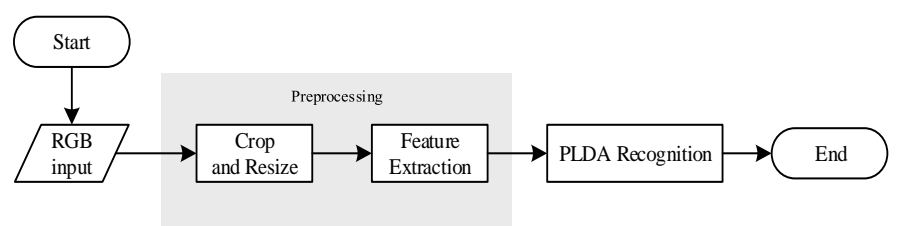

Figure 1. System Architecture

\subsection{Preprocessing}

In this study, not all of the digital image processing flow is done, because several steps are not needed for this case, for example, the image acquisition process, because the data obtained, is already in the form of a result image (not taken 
International Journal of Computer and Information System (IJCIS)

Peer Reviewed - International Journal

Vol : Vol. 01, Issue 01, May 2020

https://ijcis.net/index.php/ijcis/index

by the author himself). Based on the system design in Figure 1, the steps taken in the preprocessing data are cropping the image to get the ROI image (Region of Interest) and resize it to get the desired image size, then feature extraction with LBP and LTP to get facial representation. The steps taken in preprocessing are as follows:

\subsubsection{Crop and resize}

The process of cropping the image is done by determining the pixel point in the image that is in the middle of the image that has a face that is with the size of $250 \times 250$ and $500 \times 500$. Then after getting a new size image, a resize process is performed, which is normalizing the cropped image to a smaller image. In this study, the input image required for LBP and LTP feature extraction is $160 \times 160$

\subsubsection{Feature extraction}

Feature extraction is a very important part of a face recognition system that aims to get face representation for classification, so that face image retrieval can be done by comparing the similarity of features between one face and the other face.

The purpose of feature extraction is to get features that come from facial parts that have gone through preprocessing. At this stage feature extraction is carried out with 3 methods, namely LBP and LTP. By doing this extraction a new matrix value will be obtained and produce a feature vector from each image. So that the input used as input data in the recognition process has better quality than before.

\subsubsection{LBP (Local Binnary Pattern)}

After the original image goes through the preprocessing process of crop and resize, it will then enter the feature extraction with LBP. LBP is a simple and powerful approach to texture analysis [6]. This operator works with eight neighboring pixels, using the center pixel value as the threshold. The LBP operator is shown in Figure 2.
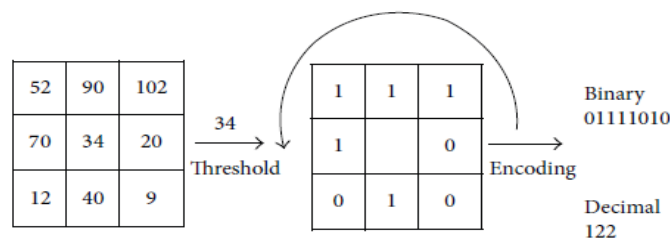

Figurer 2. LBP Operator

The LBP extraction algorithm consists of two steps, namely thresholding and encoding [7]. In the thresholding step, all neighboring pixels in each pattern are compared with the center pixel value of the pattern to change its value to binary value ( 0 or 1$)$. If the neighboring pixel has a gray value higher than the middle pixel (or equal) than the center pixel value it is worth 1 , besides that it gets a value of 0 . Then in the encoding step, the binary number obtained from the thresholding step is encoded and converted to a decimal number. In short,LBP algorithm can be seen in equation (1)

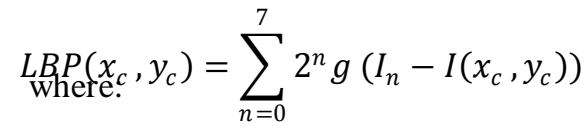

$$
\begin{array}{ll}
\left(x_{c}, y_{c}\right) & =\text { middle pixel } \\
\operatorname{LBP}\left(x_{c}, y_{c}\right) & =\text { LBP value in middle pixel }\left(x_{c}, y_{c}\right) \\
I_{n} & =\text { neighboring pixel value } \\
\text { Indeks n } & =\text { index neighboring pixel } \\
g & =\text { binary value, }\left\{\begin{array}{l}
1, I_{n} \geq\left(x_{c}, y_{c}\right) \\
0, I_{n}<\left(x_{c}, y_{c}\right)
\end{array}\right.
\end{array}
$$

The process flow in LBP method can be seen in Figure 3.

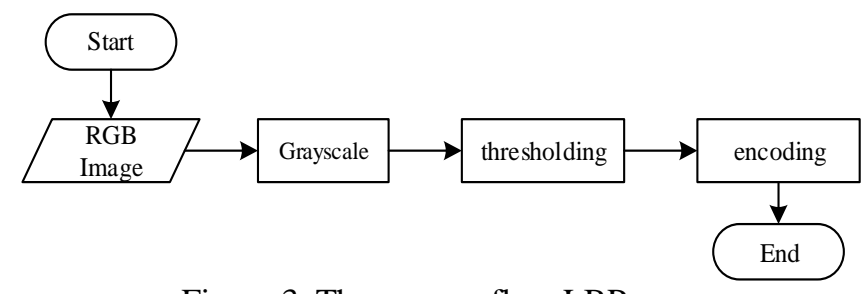

Figure 3. The process flow LBP

The stages of the LBP process are:

1. Previously, the RGB image obtained was changed to a grayscale image first.

2. The first step is to initialize the middle values $\left(x_{c}, y_{c}\right)$ and value variables that are useful for accommodating the values that will replace the middle pixel values.

3. Using conditions $I_{n} \geq\left(x_{c}, y_{c}\right)=1$ and $I_{n}<\left(x_{c}, y_{c}\right)=$ 0

4. If the condition is fulfilled, then the next step is to take the value of the middle pixel $\left(x_{c}, y_{c}\right)$ and the neighboring pixel from $I_{7}$ to $I_{0}$ the screen.

5. The next step is to compare the value of the middle pixel $\left(x_{c}, y_{c}\right)$ with neighboring pixels I_nand do the sum on the value variable according to the weight of each neighboring

$$
\mathrm{x}_{\boldsymbol{i j k}}=?_{k}+\mathrm{F}_{\boldsymbol{k}} \mathrm{h}_{\boldsymbol{i}}+\mathrm{G}_{\boldsymbol{k}} \mathrm{w}_{\boldsymbol{i j k}}+\epsilon_{\boldsymbol{i j k}}
$$

6. pixel.

7. Change all color values in the middle pixel $\left(x_{c}, y_{c}\right)$ with the value in the value variable, so that it gets a new value $\operatorname{LBP}\left(x_{c}, y_{c}\right)$.

8. Next, add the value and process the next pixel. After all, pixels are processed, the LBP result image will be formed.

\subsubsection{LTP (Local Ternary Pattern)}

A Local Ternary Pattern (LTP) is the development of the Local Binary Pattern (LBP) method. Unlike LBP which is only encoded with two values 0 and 1, LTP encodes pixels into three values $(0,1,-1)$. The LTP model of Siyang et al., 2011 [8] is defined in equation (2):

$$
\begin{aligned}
& \left(x_{c}, y_{c}\right)=\left\{\begin{array}{c}
1, \text { if } I_{n}-t<\left(x_{c}, y_{c}\right)<I_{n}+t \\
0, \text { if } I_{n}<\left(x_{c}, y_{c}\right) \\
-1, \text { if } I_{n} \leq\left(x_{c}, y_{c}\right)-t
\end{array}\right. \\
& \begin{array}{ll}
t & \text { self-determined threshold } \\
\left(x_{c}, y_{c}\right) & =\text { middle pixel } \\
I_{n} & =\text { neighboring pixel value }
\end{array}
\end{aligned}
$$

For example, a value $\mathrm{t}=5$, when the value of neighboring pixels is greater than the middle value +5 , it will be given a 
International Journal of Computer and Information System (IJCIS)

Peer Reviewed - International Journal

Vol : Vol. 01, Issue 01, May 2020

https://ijcis.net/index.php/ijcis/index

value of 1 . If the value of neighboring pixels is greater than the middle value -5 or smaller than the middle value +5 , then the value is 0 . Then if the value of pixels neighbor $\leq$ middle value -5 , then given a value of -1 . The LTP coding process is shown in Figure 4.

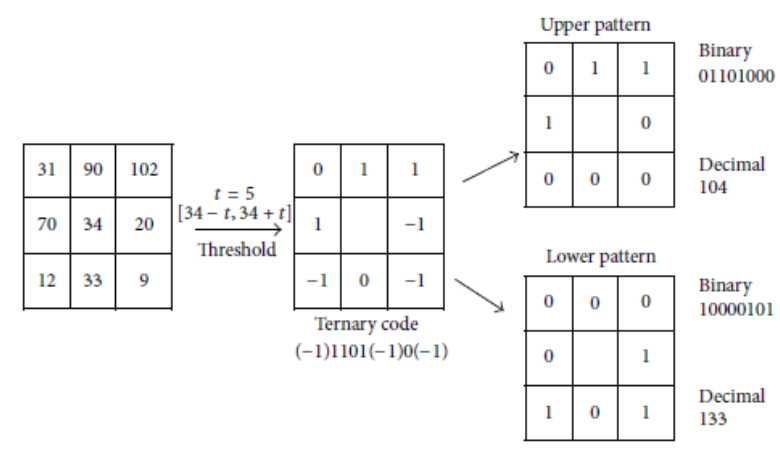

Figure 4. LTP coding process

\subsection{Designing identification model}

The method used for face recognition is Probabilistic linear discriminant analysis (PLDA). PLDA is a probabilistic generative model that is built on two latent variables that separately describe variations between classes and variations in the class [8]. We assume that the training data consists of $\mathrm{j}$ images for each. If we show the image $\mathrm{j}$ from the individuali by $\mathrm{x}_{-} \mathrm{ij}$, then the process of data generation from PLDA can be stated in equation (3)

This model consists of two parts [9]:

1. Component signals $?_{k}+\mathrm{F}_{k} \mathrm{~h}_{i}$, which only depend on people's identities, not certain images. Variables h_iare also called latent identity variables because they are unique to each individual, which can describe variations between individuals [10].

2. Different noise $\mathrm{G}_{k} \mathrm{~W}_{i j k}+\epsilon_{i j k}$ components for each image. Variables $\mathbf{w}_{i j k}$ are referred to like spaces in individuals, so the noise component reflects facial variations that are not associated with identity [11]. This explains why two images of the same individual do not look the same [12].

In general, the PLDA model can be seen in Figure 6 .

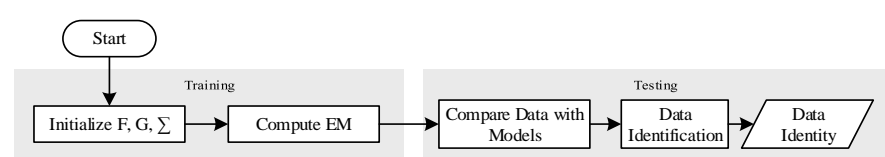

Figure 6. Designing identification model of PLDA

Based on equation (3), there are two phases in this model. At the training stage, parameter initialization F, G, $\sum$ is carried out. Then the Expectation Maximization (EM) algorithm is used for factor analysis, so this section will produce model parameters $\theta=(\mu, \mathbf{F}, \mathbf{G}, \Sigma)$. In the testing phase, an analysis of the data with the model is carried out, then identifying the data to produce data identities.

\subsection{Testing}

System testing uses face images from a collection of photos on the AR Face database. The data image used is 952 images, consisting of 136 objects with 7 facial variations per object ( 5 training data and 2 test data). So that the total number of training data is 680 images and the test data amounts to 272 images.

The system testing plan is carried out to see the characteristics and capabilities of the system made. The test in this study was conducted in two stages, namely testing the size of the input image in each feature extraction method, and testing several variations of latent dimensions with different iterations. The test design is explained in Table 1.

Table 1. Designing sistem testing

\begin{tabular}{|c|c|c|}
\hline No & Testing Design & Target \\
\hline 1 & $\begin{array}{l}\text { Testing the size of } \\
\text { the input image }\end{array}$ & $\begin{array}{l}\text { Obtained comparison of } \\
\text { extraction results from two } \\
\text { different image inputs in each } \\
\text { feature extraction used. }\end{array}$ \\
\hline 2 & $\begin{array}{l}\text { Testing } \\
\text { dimensional } \\
\text { variations }\end{array}$ & $\begin{array}{l}\text { Accuracy values obtained in the } \\
\text { feature classification process } \\
\text { with changes in feature } \\
\text { dimension values }\end{array}$ \\
\hline
\end{tabular}

\subsubsection{Testing the size of the input image}

The measurement of the input image is done by changing the input image for feature extraction with two different cropping sizes, namely $250 \times 250$ and $500 \times 500$ pixels in all extraction methods. While the resolution is adjusted to the input of each feature extraction method, which is the size of $160 \times 160$ for LBP and LTP.

This image size testing is done to see the effect and difference of the recognition that results from feature extraction with $250 \times 250$ and $500 \times 500$ image inputs, and to determine the best image size for the recognition of these two inputs.

\subsubsection{Testing of dimensional variations}

Dimensional testing is done by making variations on the dimensions used for the recognition of PLDA, including 25 , $50,75,100,125,150,175,200,225,250$ with iterations 1 , 3 , and 5 . This test is done to classify faces based on texture characteristics so that the results of the recognition of the object will get an accuracy value. The final accuracy of this test data shows the performance of the proposed recognition method.

\section{RESULT AND ANALYSIS}

This section discusses the results of face recognition testing of the models that have been built by measuring the accuracy values obtained. The total image used is 952 images, with the total number of training data is 680 images and the test data is 272 images.

In this study, 10 experiments were conducted on the values of $F$ and $G$ subspace dimensions, as well as with iterations 1,3 , and 5 with $250 \times 250$ and $500 \times 500$ image inputs. This is done to find the best input dimensions and sizes to produce maximum facial identity searches obtained from the most correct identification of faces. To compare the performance of each method, it will be compared to the average of the results obtained. The average results of recognition accuracy can be seen in Table 2 and Table 3 . 
International Journal of Computer and Information System (IJCIS)

Peer Reviewed - International Journal

Vol : Vol. 01, Issue 01, May 2020

https://ijcis.net/index.php/ijcis/index

Table 2. Average accuracy of PLDA recognition with $250 \times 250$

\begin{tabular}{cccc}
\hline $\boldsymbol{d}_{\boldsymbol{F}}$ & $\boldsymbol{d}_{\boldsymbol{G}}$ & $\mathbf{L B P}$ \% & LTP \% \\
\hline 25 & 25 & 48,65 & 73,53 \\
50 & 50 & 53,06 & 79,41 \\
75 & 75 & 56 & 80,27 \\
100 & 100 & 63,11 & 82,96 \\
125 & 125 & 71,08 & 83,33 \\
150 & 150 & 69,73 & 87,13 \\
175 & 175 & 78,06 & 86,15 \\
200 & 200 & 78,06 & 86,89 \\
225 & 225 & 79,66 & 90,93 \\
250 & 250 & 78,19 & 89,46 \\
\hline
\end{tabular}

Table 3. Average accuracy ofPLDA recognition with $500 \times 500$

\begin{tabular}{cccc}
\hline $\boldsymbol{d}_{\boldsymbol{F}}$ & $\boldsymbol{d}_{\boldsymbol{G}}$ & LBP \% & LTP \% \\
\hline 25 & 25 & 91,42 & 92,16 \\
50 & 50 & 92,77 & 93,75 \\
75 & 75 & 93,01 & 93,5 \\
100 & 100 & 92,89 & 94,48 \\
125 & 125 & 93,63 & 95,46 \\
150 & 150 & 93,5 & 95,46 \\
175 & 175 & 93,5 & 95,46 \\
200 & 200 & 93,14 & 96,2 \\
225 & 225 & 94,12 & 96,69 \\
250 & 250 & 93,38 & 94,12 \\
\hline
\end{tabular}

Data on the accuracy of LBP and LTP results at the end of the experiment were evaluated and seen the dimensions of the method which was the most optimal and had the highest accuracy, because the core of this study was to find out the level of recognition of the system in LBP and LTP.

The test results on the input and dimensions of the feature extraction method used in the recognition of PLDA can be seen in Table 4.

Table 4. Testing Result

\begin{tabular}{lllll}
\hline Method & $\boldsymbol{d}$ & $\mathbf{2 5 0 \times 2 5 0}$ & $\boldsymbol{d}$ & $\mathbf{5 0 0 \times 5 0 0}$ \\
\hline LBP & 225 & $83,45 \%$ & 225 & $95,59 \%$ \\
LTP & 225 & $94,12 \%$ & 225 & $98,53 \%$ \\
\hline
\end{tabular}

Based on the results of all the experiments that have been conducted, it can be seen in general that the use of LTP for feature extraction is better than LBP. This can be seen from the level of accuracy.

\section{CONCLUSIONS}

Based on the research that has been done, the following conclusions are obtained:

1. Characteristics of texture produced by extraction with a Local Ternary Pattern (LTP) are more optimal than the texture traits produced by extraction of Local Binary Pattern (LBP) and Local Ternary Pattern (LTP).

2. A wider image input size results in more correct face recognition.

3. The highest accuracy that can be generated from the extraction of LTP is $95.59 \%$ at the input size of $500 \times$ 500 , while for LBP it is $94.12 \%$ in the input of the same size.
4. The use of LBP and LTP texture characteristics as input to PLDA can overcome the problem of gray image input, because the texture characteristics produced by LBP and LTP are not affected by lighting differences, so pixels are generated by encoding the image the image of the training data and the image of the test data are almost the same. In this study still have deficiencies that can be improved. some suggestions for further research are as follows: This research is still limited to a small amount of data, then experiments can be carried out for other cases with more data and larger feature dimensions. Increase the variation of experiments on LBP and LTP for example variations in the size of neighboring pixels $16 \times 16$.

\section{REFERENCES}

Hamouchene, I., Aouat, S., dan Lacheheb, H., 2014, Texture Segmentation and Matching Using LBP Operator and GLCM Matrix, In Intelligent Systems for Science and Information, Springer, Algeria, hal. 389-390.

[2] Arriawati, A. J., Santoso, I., dan Christyono, Y., 2011, Pengenalan Citra Tekstur Menggunakan K-Nearest Neighbour Berdasarkan Ekstraksi Ciri Metode Matriks Kookurensi,. Jurusan Teknik Elektro, Fakultas Teknik, Universitas Diponegoro, Semarang.

[3] Hidayat, R., 2015, Studi Komparasi Metode Ekstrasi Ciri Wajah Untuk Pengenalan Ekspresi Wajah Manusia Berbasis Pengolahan Citra Digital,. Universitas Gadjah Mada, Yogyakarta.

[4] Wibowo, M. E., Tjondronegoro, D., dan Zang, L., 2012, On the application of the probabilistic linear discriminant analysis to face recognition across expression, In IEEE International Conference on Multimedia and Expo Workshops (ICMEW ), Melbourne, hal. 459-464.

[5] Maturana, D., Mery, D., dan Soto, Á., 2010, Face recognition with local binary patterns, spatial pyramid histograms and naive bayes nearest neighbor classification, In Proceedings - International Conference of the Chilean Computer Science Society, SCCC, Chile, hal. 125-132.

Ojala, T., Pietikainen, M., dan Harwood, D., 1996, A comparative study of texture measures with classification based on feature distributions, Pattern Recognition, 29, 1, $51-59$.

[7] Rassem, T.H. dan Khoo, B.E., 2014, Completed Local Ternary Pattern for Rotation Invariant Texture Classification, The Scientific World Journal, 1-10.

[8] El Shafey, L.E., 2014, Scalable Probabilistic Models for Face and Speaker Recognition,. Faculté des Sciences et Techniques de l'Ingénieur laboratoire de l'IDIAP, Lausanne,

[9] Prince, S.J.D. dan Elder, J.H., 2007, Probabilistic Linear Discriminant Analysis for Inferences About Identity,

[10] Wibowo, M. E., Tjondronegoro, D., dan Zang, L., 2012, On the application of the probabilistic linear discriminant analysis to face recognition across expression, In IEEE International Conference on Multimedia and Expo Workshops (ICMEW ), Melbourne, hal. 459-464.

[11] Shaikh, M.K., Tahir, M.A., dan Bouridane, A., 2014, 
International Journal of Computer and Information System (IJCIS)

Peer Reviewed - International Journal

Vol : Vol. 01, Issue 01, May 2020

https://ijcis.net/index.php/ijcis/index

PROBABILISTIC

LINEAR

DISCRIMINANT

ANALYSIS FOR INTERMODALITY FACE

RECOGNITION, In IEEE International Conference on Acoustic, Speech and Signal Processing (ICASSP), hal. 509-513.,

[12] Li, P., Fu, Y., Mohammed, U., Elder, J.H., dan Prince, S.J., 2012, Probabilistic Models for Inference about Identity, IEEE Transactions on Pattern Analysis and Machine Intelligence, 34, 1, 144-157. 